\title{
Mammalian septins in health and disease
}

\author{
This article was published in the following Dove Press journal: \\ Research and Reports in Biochemistry \\ 25 February 2015 \\ Number of times this article has been viewed
}

\section{Cristina Montagna ${ }^{1,2}$ Michal Bejerano-Sagie Jenna R Zechmeister ${ }^{3}$ \\ 'Department of Genetics, ${ }^{2}$ Department of Pathology, Albert Einstein College of Medicine, Yeshiva University, ${ }^{3}$ Department of Obstetrics and Gynecology and Women's Health, Montefiore Medical Center, New York, NY, USA}

\begin{abstract}
Septins embrace a large family of proteins highly conserved among eukaryotic species. They were originally identified in budding yeast in the early 1970 s as proteins essential for completion of cytokinesis. In humans, septins comprise a group of 13 genes, most of which are present in several isoform variants, leading to a complex pattern of expression. The biological functions achieved by septins have been extensively investigated in yeast, and while several questions remain unanswered, details on the mechanisms of action and pathways relative to their major role in orchestrating the mitotic process, cell polarity, and diffusion barriers have been elucidated. In mammalian cells, the biological processes in which septins play important roles are emerging as increasingly complex. Septins are found with a broad range of expression in most tissues, and like in yeast, are essential for the successful completion of cytokinesis and for the establishment of cell polarity and diffusion barriers. However, they have also been shown to be important for phagocytosis and migration. Owing to their widespread expression in most mammalian cell subtypes and the plethora of functions to which they have been associated, it is not surprising that septins have been implicated in a large variety of human diseases. This review summarizes the current knowledge of septins' cellular functions and the mechanisms of regulation of their assembly. In addition, we present the broad range of human diseases where septins have been shown to be important for the etiology of the disease, including areas where septins have been recently implemented as biomarkers. Because of the growing evidence supporting the association of septins with novel cellular and biological functions, we expect this intriguing family of cytoskeletal interacting proteins to become coupled with an increasing number of human diseases.
\end{abstract}

Keywords: septins, cytoskeleton, disease, oncogenes, biomarkers, cancer

\section{Introduction}

Septins comprise a large family of cytoskeletal interacting filaments originally identified in yeast as proteins essential for cytokinesis that associate with the $10 \mathrm{~nm}$ filaments found at the cytoplasmic interface of the plasma membrane in the mother-bud neck. ${ }^{1-3}$ Septins are highly conserved from yeast to humans, and are expressed in variable number of gene-family components in all species but higher plants. ${ }^{3}$ However, recent studies aimed at characterizing the phylogenetic distribution and evolutionary origins of septins suggest that they are also present in chlorophyte algae, brown algae, and ciliates. $^{4}$

The distinguishing characteristic of septins, which is also essential for the accomplishment of their biological functions, is their ability to organize into oligomeric core complexes that ultimately assemble into higher-order structures such as filaments, ${ }^{1,5,6}$ cages ${ }^{7}$ rings, ${ }^{8,9}$ and gauzes (Figure $\left.1 \mathrm{~A}-\mathrm{C}\right) .{ }^{10}$ 

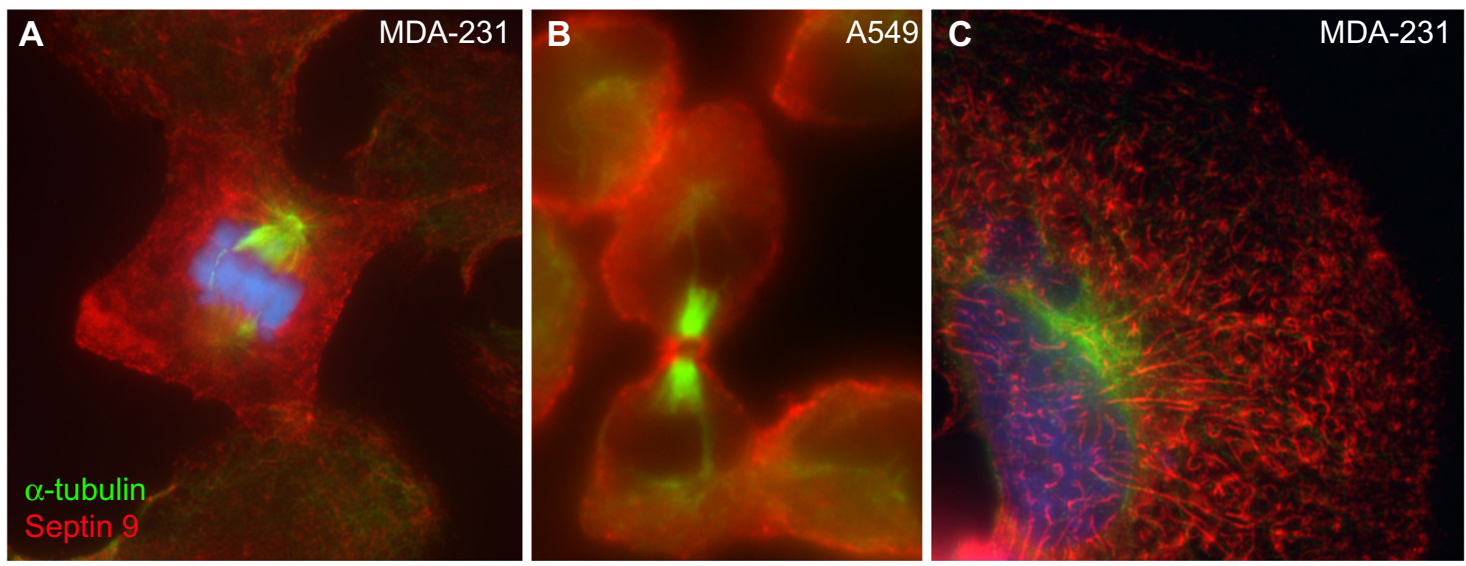

D

Common domains

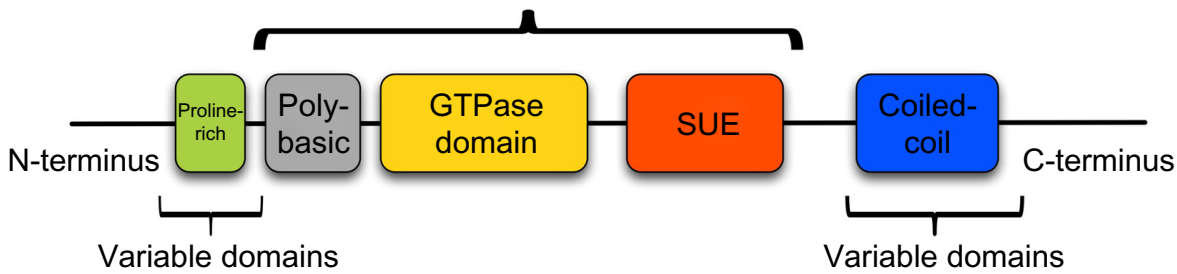

Figure I Representative images of organization of SEPT9 filaments in mammalian cells at different stages of the cell cycle.

Notes: (A) In early anaphase, SEPT9 filaments (red) disassemble and can be observed as punctuated staining in the cytoplasm, as well as more filamentous structures along the plasma membrane. (B) During late telophase, SEPT9 staining is visible as a ring structure along the cleavage furrow, resembling the morphology of budding yeast. (C) In interphase cells, SEPT9 assembles into filaments whose morphology varies between rings and filaments in different cell lines. In MDA-23I cells, both filaments and rings are clearly visible. (D) Schematic representation of septin domains: proline-rich domain (green), polybasic domain (gray), GTPase domain (yellow), SUE domain (orange) and the coiled-coil domain (blue). Images for (A-D) were acquired in Dr Cristina Montagna laboratory at Albert Einstein College of Medicine.

Abbreviation: SUE, septin-unique element.

Septins are defined by the ubiquitous presence of several motif sequences (Figure 1D). All septins share the unique element, a conserved region orthologous to amino acids $360-413$ of Saccharomyces cerevisiae Cdc3p. ${ }^{11}$ Mammalian septins comprise 13 genes (SEPT1-SEPT12 and SEPT14; owing to $S E P T 13$ being characterized as a pseudogene and now defined as $S E P T 7 P 2$ ) that are subclassified into four groups defined based on their homology sequence. ${ }^{12-15}$ The SEPT3 subgroup includes SEPT3, SEPT9, and SEPT12, and lacks the coiled-coil C-terminus domain. Loss of this domain in yeast and Ashbya gossypii, a filamentous fungus, shows aberrant morphology and defects in neck structures, and results in failure of cytokinesis. ${ }^{16,17}$ In yeast, the coiledcoil domain has been shown to be essential for proper localization of Cdc11 (one of the five yeast mitotic septins) and is important for interaction with septin Cdc3 and the bud emergence gene Bem $4 .{ }^{16}$ While a definite role for the coiled-coil domain in mammalian cells remains elusive, several lines of evidence suggest that it is important for the assembly and stability of septin filaments. ${ }^{18,19}$ The SEPT2 subgroup includes SEPT2, SEPT1, SEPT4, and SEPT 5; the $S E P T 7$ subgroup includes only $S E P T 7$, which in some studies is defined as a SEPT2 subgroup together with SEPT13; and the SEPT6 subgroup includes SEPT6, SEPT8, SEPT10, SEPT11, and SEPT14.

In addition to the septin-unique element and the coiledcoil domain (present in most septins) the 13 human septins all share a central highly conserved core domain consisting of a GTP-binding region of the P-loop superfamily of GTPases (Walker A motif -P-loop/G1 motif, as well as sequences resembling G3 and G4 motifs) flanked by a polybasic region. ${ }^{20,21}$ These domains allow the formation of a flexible loop, and are important for the binding of $\mathrm{Mg}^{2+}$, and can also interact with $\beta$ - and $\gamma$-phosphates of GTP. The GTPase motif is important for GTP-binding specificity. Despite the presence of a shared GTP-binding domain in all members of the septin family, the dynamics of GDP/GTP binding as well as the requirement for GTP hydrolysis to fulfill septin biological functions remains to be elucidated. Some reports suggest that only septin complexes and not single septins are capable of binding appreciable amounts of guanine nucleotide, ${ }^{22}$ while others suggest that septin monomers may also have the ability to bind and hydrolyze GTP. ${ }^{11}$ Independently of the organizational status that may allow for binding, all septins have been shown to possess the ability to bind GDP. Members of groups SEPT2, SEPT7, and SEPT9 present low 
intrinsic GTP activity with the ability to hydrolyze GDP, ${ }^{21}$ while members of the SEPT6 group lack this property. ${ }^{23}$ It has been suggested that loss of the intrinsic GTP hydrolysis is a specific feature of organisms like humans having a large number of septins; however, the reason for these findings remains unclear. Binding of GTP has been shown to induce the characteristic conformational change that operates as the common mechanism of function of GTPases of the Rasrelated superfamily. ${ }^{24,25}$ The main question of whether hydrolysis is required for septins' assembly, and if conformational changes of the GTP-binding region affect the dynamics of septin filaments, remains largely unknown.

A highly conserved polybasic region flanks the GTPbinding domain at the N-terminus of the septin-protein sequence (Figure 1D), and it is responsible for the interaction and binding of septins with the cell membrane. ${ }^{26}$ Upstream of the polybasic region, septins contain a proline-rich domain, a sequence important for protein-protein interactions and frequently involved in the interaction of proteins with cytoskeletal components. ${ }^{27,28}$ Adding to the complexity of septins is the complex transcriptome that is emerging. All members but SEPT14 encode various isoform variants (Table 1) for a total of 81 transcripts. Micro-ribonucleic acids (miRNAs) and antisense transcripts have been recently annotated to the septins' genomic regions (Gencode version 19), suggesting that tightly regulated mechanisms of transcriptions may take place to orchestrate the expression of this complex gene family.

\section{Dynamics and regulation of septins}

The main characteristic of septins is their ability to assemble into filaments. Assembly of septins is achieved via organization of heteroligomeric complexes that ultimately organize into higher-order structures. ${ }^{20,29}$ While the role that GTP hydrolysis plays in the assembly of septin filaments remains largely unknown, electron microscopy studies ${ }^{18,30}$ and the crystal structure of the main septin complex ${ }^{31}$ have provided important insights into the structure and organization of septin filaments.

Using the $G$ domain, each member of the septin family has the ability to dimerize in tandem with itself or with another septin member and organize into an apolar hexameric complex. The best characterized of these hexamers to date is the SEPT2-SEPT6-SEPT7 complex. ${ }^{31}$ By crystallography analyses, it was revealed that these three members of the septin family could arrange in one hexamer that is oriented as SEPT7-SEPT6-SEPT2-SEPT2-SEPT6-SEPT7 (Figure 2). Septin monomers interact by two interfaces: the $G$ domain and the $\mathrm{N}$ - and $\mathrm{C}$-terminal domains. End-to-end binding of these nonpolar oligomers yields to the assembly of linear filaments that can additionally pair through their coiled-coil domain to produce bundles. ${ }^{8,18,32}$ Septins can also bind to lipids via their polybasic region, a feature that may aid their tridimensional organization. ${ }^{26}$

Several different compositions of the septin hexamers have been described thus far. While it remains unknown if all members of the septin gene family can substitute each other in the assembly of filaments, it is recognized that septins follow a combinatorial mode where some members have higher affinity for one another. ${ }^{13}$ While septins are ubiquitously expressed in all tissues, there is specificity in which member/s of the family may be expressed in a given cell subtype. Therefore, the mode of assembly of the septin filaments may likely be tissue-specific and depend on which

Table I Chromosomal mapping and transcriptional variants of Septin family members

\begin{tabular}{|c|c|c|c|c|c|c|c|}
\hline \multirow{2}{*}{$\begin{array}{l}\text { Septin } \\
\text { member }\end{array}$} & \multirow[t]{2}{*}{ Chromosome } & \multirow{2}{*}{$\begin{array}{l}\text { bp Mapping on } \\
\text { chromosome }\end{array}$} & \multirow{2}{*}{$\begin{array}{l}\text { Size of genomic } \\
\text { locus (bp) }\end{array}$} & \multicolumn{4}{|c|}{ Number of Gencode (version 19) variants } \\
\hline & & & & Coding & miRNA & Antisense & Other \\
\hline SEPTI & 16 & chrl6:30,389,454-30,394,|7| & 4,718 & 3 & - & - & 1 \\
\hline SEPT2 & 2 & chr2:242,254,602-242,293,44I & 38,840 & 6 & - & I & 1 \\
\hline SEPT3 & 22 & $\operatorname{chr} 22: 42,372,931-42,394,225$ & 21,295 & 5 & - & I & - \\
\hline SEPT4 & 17 & $\operatorname{chr} \mid 7: 56,597,6 \mathrm{II}-56,606,828$ & 21,295 & 10 & - & 4 & - \\
\hline SEPT5 & 22 & chr22:19,70I,987-19,7|0,845 & 8,859 & 4 & - & - & 1 \\
\hline SEPT6 & $x$ & chrX:I I8,750,909-II8,827,333 & 76,425 & 8 & 1 & - & 1 \\
\hline SEPT7 & 7 & chr7:35,840,596-35,946,7।5 & 106,120 & 7 & 1 & - & 1 \\
\hline SEPT8 & 5 & chr5:| 32,09|,695-|32||2980 & 26,559 & 8 & - & - & 1 \\
\hline SEPT9 & 17 & chr I7:75,277,492-75,496,674 & 219,187 & 15 & 2 & 2 & I \\
\hline SEPTIO & 10 & chr2:II0,303,626-1 I0,343,400 & 71,410 & 7 & - & - & I \\
\hline SEPTII & 4 & chr4:77,870,895-77,959,768 & 88,874 & 5 & - & - & 1 \\
\hline SEPTI2 & 16 & $\operatorname{chr} \mid 6: 4,827,615-4,838,522$ & 10,908 & 2 & - & - & 1 \\
\hline SEPTI4 & 7 & chr7:55,86I,237-55,930,482 & 69,246 & 1 & - & - & 1 \\
\hline Total & & & 724,896 & 81 & 4 & 8 & 11 \\
\hline
\end{tabular}

Abbreviations: bp, base pairs on chromosome; miRNA, micro-ribonucleic acid. 


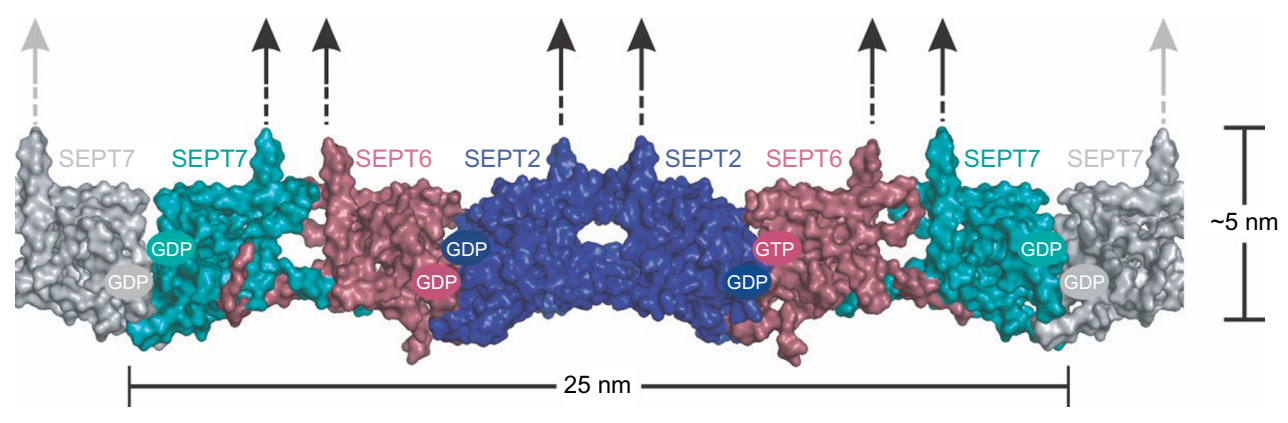

Figure 2 Representation of the crystal structure of the SEPT7, SEPT2, and SEPT2 complex.

Notes: The $25 \mathrm{~nm}$ septin-filament length comprises a hexamer assembled via direct interaction of the SEPT7, SEPT2, and SEPT2 trimer. The arrows represent the presumed orientations of the C-terminal ends. Reprinted with permission from Macmillan Publishers Ltd: Sirajuddin M, Farkasovsky M, Hauer F, et al. Structural insight into filament formation by mammalian septins. Nature. 2007;449:3 II-315. (C Copyright 2007. ${ }^{31}$

septin is available. The septin complexes that have been thus far isolated from tissue-culture cells include a canonical complex of SEPT2-SEPT6-SEPT7, ${ }^{8,33}$ SEPT3-SEPT5-SEPT7, ${ }^{34}$ and SEPT5-SEPT7-SEPT $11 .{ }^{35}$ Complexes containing SEPT9 have been described: SEPT7-SEPT9-SEPT11 ${ }^{36}$ and SEPT2-SEPT6-SEPT7-SEPT9. ${ }^{37}$ These are particularly interesting to understand mechanisms that lead to filament assembly. SEPT9 was not originally included in the complex analyzed by crystallography; however, biochemical and immunofluorescence studies suggest that SEPT9 is part of the SEPT2-SEPT6-SEPT7 complex. ${ }^{38,39}$ The most current model suggests that SEPT9 occupies a terminal position in the native octameric complex, and that removal of the SEPT9 $\mathrm{N}$-terminal domain disrupts septin higher-order structures, leading to failure of cytokinesis. ${ }^{37,40}$

To date, SEPT7 appears to be a recurrent component of the septin complexes, while SEPT9 is present at the terminal position of septin complexes and is suggested to be responsible for subunit polymerization. ${ }^{40}$ Based on these observations, it is intriguing that among the septin-knockout murine models that have been generated thus far (Sept3, Sept4, Sept5, Sept6, Sept7, Sept9, and Sept11) the first four have mild phenotypes, while constitutive deletion of Sept7, Sept9, and Sept11 results in embryonic lethality at early gestation. ${ }^{41}$ These data suggest that while several septins could be interchangeable, some others may be required for the assembly and/or function of the filaments.

Septins bind to microtubules through their N-terminal domain, ${ }^{42}$ they are recruited to actin bundles via their interaction with adaptor proteins, ${ }^{43}$ and they are required for packing actin filaments into rings. ${ }^{44}$ Because of their close interactions with the cytoskeleton, they were originally considered structural proteins. However, it is now evident from work performed both in yeast and mammalian cells that they also have important regulatory functions, as well as serving as docking sites for anchoring other regulatory proteins involved in a variety of cellular processes. Numerous septin-interaction partners that are part of the ubiquitination and of the kinase cascade pathways have been identified; ${ }^{45,46}$ in mammalian cells, septins have also been implicated in the process of exocytosis by assembling into tracks for vesicle transport and are also important for the establishment of cell polarity, ${ }^{47}$ as well as regulators of synaptic vesicle dynamics. ${ }^{48}$

Therefore, while septins interact with one another and assemble into filaments, their functions greatly extend beyond that of structural filaments by providing regulatory functions for a wide variety of cellular processes.

\section{Biological functions of septins}

Septins are involved in a large number of biological functions. Several decades of work carried out in yeast has provided extensive evidence of the septin filaments' role as scaffolding proteins. For example, at the mother-bud neck interface, where septins localize during cell division, septins have been shown to be essential recruiters of a large number of proteins that are essential for cytokinesis. ${ }^{49-51}$ Contrary to what was originally thought, the septin ring that assembles at the septum seems not to be required to generate the dynamic forces required for cytokinesis, but rather provides essential regulatory functions..$^{52,53}$ Assembly of the septin scaffold in yeast is required for microtubule capture and positioning of the spindle-pole body and subsequent segregation of replicated chromosomes into the mother and daughter cells. ${ }^{54}$ In addition to their scaffolding function at the mother-bud neck interface, septins also function as a diffusion barrier by limiting the exchange of cortical factors through the bud neck. ${ }^{5-57}$

In mammalian cells, septins regulate a large variety of key cellular processes, including ciliogenesis and neurogenesis, 
and like in yeast they are necessary for cytokinesis, where they function as diffusion barriers to compartmentalize discrete cellular domains. ${ }^{58}$

Similarly to yeast, mammalian cells also organize septin rings at the site of cytokinesis (Figure 1B). However, their function as diffusion barriers has not been investigated as extensively as in yeast. Cortical barriers to diffusion within the cleavage furrow of mammalian cells are known to be present at the mid-body; however, the contribution of septins to this structure remains largely unknown. ${ }^{59}$ An example of the function that septins provide in establishing diffusion barriers is provided by the cilia, at the base of which septins form a ring-like structure..$^{58}$ The primary cilium is an organelle protruding from the apical surface of most cells in a variety of vertebrate cells. Primary cilia function as sensory receptors, and have been established as key coordinators of signaling pathways during development and tissue homeostasis. Defects in structure and function of this organelle are a major cause of human diseases and developmental disorders known as ciliopathies. ${ }^{60}$ While the membrane of the cilia fuses with the plasma membrane during ciliogenesis, it retains a unique set of proteins that sense and transduce a variety of extracellular signals. A septin-containing diffusion barrier is present at the base of the ciliary membrane, and has been shown to be required for the retention of receptor-signaling pathways in the primary cilium. This diffusion barrier restricts the diffusion of ciliary membrane proteins between the ciliary and periciliary membrane, providing a classic example of evolutionarily conserved roles of septins from fungi to mammals (ie, the establishment of compartmentalization of membrane domains). ${ }^{61}$ Similar to what is observed at the base of the primary cilia, a septin-diffusion barrier also forms a ring at the sperm annulus. The sperm annulus, which is required for the cortical organization, morphology, and normal motility of sperm flagella, is a septin-based structure composed of several septins, such as SEPT1, SEPT4, SEPT6, SEPT7, and SEPT12. ${ }^{62-64}$

Reminiscent of septin localization at the base of protrusions, septins were shown to cluster at the base of dendritic spines. ${ }^{65}$ Several members of the septin family, including Sept7, were found by a general screening of the hippocampal neurons of rats using mass spectrometry of postsynaptic density fractions. Sept7 is localized at the base of dendritic protrusions and at dendritic branch points. Overexpression of Sept7 leads to increased dendrite branching and density of dendritic protrusions, which suggests Sept7 is critical for spine morphogenesis and dendrite development during neuronal maturation.
Septin functions are not restricted to the central nervous system, but they may also play important roles in the peripheral nervous system. By mass spectrometry of highly purified extracts of myelin isolated from mouse sciatic nerves Sept2, Sept7, Sept9, and Sept11 were found to be expressed. ${ }^{66,67}$

Like yeast septins, the mammalian homologs are required for establishment and maintenance of cell polarity. ${ }^{55,68}$ Cell polarity is a fundamental process essential for the development and physiological functions of organisms and tissues. A common characteristic of polarized cells is the presence of an asymmetric organization of the plasma membrane. At the cellular level, the establishment and maintenance of cell polarity follows common processes in different organisms. Similar to yeast, mammalian cells establish polarity using the highly conserved Ras and Rho-like family of GTPases. ${ }^{69}$ Establishment of cell polarity requires membrane trafficking of vesicles along cytoskeleton tracks that connect donor to acceptor membranes. Yeast has proven to be an extraordinary model to study mechanisms for establishment and regulation of cell polarity. ${ }^{70,71}$ A role for septins in mammalian cell polarity also seems to be established. During polarization of MDCK cells in vitro, SEPT2 guides the directionality of growth and capture of microtubules plus end, a process that is essential for maintaining proper orientation of microtubules. ${ }^{72}$ Previous studies have uncovered that septins control microtubule stability through their association with MAP4, microtubule acetylation, and binding to polyglutamated microtubules. ${ }^{27,38,73-75}$

Mammalian septins, just like yeast septins, are essential for the completion of cytokinesis. Microinjection of affinity-purified anti-SEPT9 antibodies as well as depletion of SEPT2, SEPT7, and SEPT11, using small interfering RNA causes defects in the early and late stages of cytokinesis, ultimately resulting in binucleation or failure of final separation of daughter cells. ${ }^{38,39}$ For successful completion of cell division, it is essential that coordination between cytokinesis and chromosome segregation is established. Some septins have been shown to localize at the metaphase plate during cell division. Using antibodies against SEPT2 and SEPT6, Spiliotis et al reported both proteins localized within the microtubule spindle in close apposition to the kinetochores. ${ }^{73}$ Septin (SEPT2 and SEPT6) depletion by small interfering RNA resulted in chromosome loss from the metaphase plate, lack of chromosome segregation, and spindle elongation. These defects correlated with loss of the mitotic motor and the checkpoint regulator centromereassociated protein $\mathrm{E}$ from the kinetochores of congressing chromosomes. 
Lastly, studies of host-microorganism interactions have surprisingly uncovered roles for septins during bacterial infection and innate immunity. Septins were first linked to the process of phagocytosis based on the known function they play in regulating membrane traffic. Several septins are expressed in mouse macrophage cell lines, and Sept2 and Sept11 were shown to localize to the phagosomes. ${ }^{76}$ Shortly thereafter, it began emerging that septins play an essential role in mechanisms of protection against infection by pathogens. Work performed mainly on Listeria and Shigella has shown that septins assemble into a caging as a mechanism of host defense that controls the fate of cell-to-cell spreading. ${ }^{7,77}$ Regulation of membrane dynamics was also shown to be crucial for T-lymphocyte migration. ${ }^{78}$ Septins assemble along the cell cortex, providing a scaffolding structure. Elimination of the septin cytoskeleton using small hairpin RNA results in morphological alterations of $\mathrm{T}$ cells, which causes pronounced blebbing and excess leading-edge protrusions.

The resulting disorganized migration of septin-deficient cells strongly suggests a corset-like function for the septin cytoskeleton, providing compression and rigidity, and supporting efficient motion of motile $\mathrm{T}$ cells. Interestingly, conditional deletion of Sept 9 in mouse $\mathrm{T}$ cells by using a Sept9-floxed system driving deletion under the control of Lck-Cre expression results in a delay of T-cell development. ${ }^{79}$

\section{Septin-associated human diseases}

The septin family of cytoskeleton-related proteins have been implicated in a wide variety of mammalian pathologic conditions.

\section{Neurological conditions}

With respect to neurological illnesses, septins are thought to be involved in disease states spanning both neurodegenerative conditions and neurobehavioral disorders. Alzheimer's disease is a progressive neurodegenerative disorder that is histopathologically characterized by the presence of senile plaques as well as neurofibrillary alterations. SEPT2 (NEDD5), SEPT1 (DIFF6), and SEPT4 (H5) have been shown to be concentrated in the neurofibrillary tangles of Alzheimer's patient brains, potentially suggesting a role in the neurodegenerative process. ${ }^{80}$ In another common neurodegenerative disorder, Parkinson's disease, SEPT4 is thought to have a role in cell death and the formation of Lewy body cytoplasmic inclusions containing $\alpha$-synuclein. ${ }^{81,82}$ Proteomic studies performed on postmortem brains of patients with schizophrenia and bipolar disorder demonstrated differential expression of septins in both diseases..$^{83}$ Deregulation of several proteins in the cerebral cortex of fetuses with Down syndrome included a decrease in the level of SEPT7, suggesting involvement in the developmental and cognitive impairment in this disease. ${ }^{84}$ The mass-spectrometry findings that postsynaptic densities contain several members of the septin gene family ${ }^{65,85}$ support their possible implication in neurodegeneration and loss of cognitive function. In addition, these results are intriguing, given that the brain is a tissue composed mainly of postmitotic cells, and therefore in the brain, members of the septin family of genes are likely to carry on essential functions that are not strictly linked to cytokinesis. While a definitive role for septins in the etiology of neurodegenerative disorders at the cellular level remains unknown, we could speculate that septins in these cells contribute to the formation of cellular aggregates characteristic of these diseases. For example, septin filaments that normally support the tridimensional structure and shape of the cells may become unfolded, leading to the generation of aggregates that could possibly disrupt cell function and ultimately lead to cell death.

\section{Hereditary neuralgic amyotrophy}

SEPT9 is one of the most complex members of the septin gene family (Table 1). It was originally identified as a region of loss of heterozygosity in breast and ovarian cancer, ${ }^{86}$ and is characterized by expression of 18 putative alternated transcripts. ${ }^{87}$ Mutations in the N-terminal portion of the SEPT9 sequence have been discovered in hereditary neuralgic amyotrophy (HNA), a neuropathy with autosomal-dominant inheritance, clinically characterized by motor and sensory deficits of the muscles innervated by the brachial plexus. The earliest research conducted on HNA discovered the missense mutations R88W and S93F; individuals with these mutations display similar dysmorphic features, such as hypotelorism and epicanthal folds, while other mutations have no dysmorphic features. ${ }^{88,89}$ More recent research has uncovered that duplications within the SEPT9 gene occur in families with HNA, and have also provided further evidence for the current known mutations. ${ }^{90,91}$ The exact mechanism of action by which mutations in SEPT9 are linked to HNA remains to be elucidated, although some evidence is starting to emerge. The original mutations identified in HNA patients - SEPT9F (c.278C $>$ T/p.Ser93Phe) and SEPT9W (c.262C > T/p. Arg88Trp) - both mapping to SEPT9 isoform _v3 were introduced in NMuMG, a nontransformed mouse mammary epithelial cell line. ${ }^{92}$ The mutants, but not the wild type, were found to form filaments with SEPT4 and to colocalize with SEPT11 at cell-cell junctions, suggesting that sequence 
variations in SEPT9 causing HNA are likely to alter modes of interaction with partner molecules in cells. Likewise, HNA mutation R88W mapping to the N-terminus of SEPT9 resulted in diminished intracellular microtubule bundling and impaired asymmetric neurite growth in pheochromocytoma rat PC-12 cells. ${ }^{42}$ Interestingly mice harboring an inactivated prion-protein gene (Prnp0/0), a model for a chronic polyneuropathy, have increased level of SEPT9 expression, as well as a characteristic localization in Schwann cells of the protein that appears associated with intracellular transport vesicles. ${ }^{67}$ This observation provides insight into possible mechanisms of SEPT9 function in HNA.

\section{Infertility}

Another spectrum of disease that septins have been connected to is male infertility. Studies conducted on infertile male subjects showed mutations leading to a nonfunctional SEPT12 protein that affected both structure and function of the sperm causing oligoasthenozoospermia and asthenoteratozoospermia. ${ }^{93}$ Interestingly also, mice lacking the homozygous expression of Sept 4 are sterile. ${ }^{63}$ Both human sperm expressing mutant SEPT12 and mouse sperm lacking Sept4 expression show cells with similar morphological defects, including severely bent tails, large droplets of cytoplasm at the area of the cell that surrounds the nucleus, and a structurally defective annulus. These observations suggest that loss of septin functions in these cells disrupts the structural integrity of the sperm required for egg fertilization, and similarly to defects in vesicle trafficking and exocytosis, may impair a necessary process of droplet formation and dynamics required for motility. ${ }^{43}$

\section{Tumorigenesis}

While severely affecting the organism, the aforementioned diseases are not lethal. Septins have however been long linked to malignancy, and are implicated in cancer both with tumorigenic and suppressive potential involving multiple organ systems and varieties of histology. They were first implicated in tumorigenesis with the discovery of their fusion to the MLL gene in hematologic malignancies. ${ }^{94,95}$ Commonly in leukemias, gene fusion occurs via a genetic rearrangement of a fusion partner with the MLL locus mapping to 11q23, so that the N-terminal portion of the MLL protein fuses to the C-terminal portions of the fusion partner. ${ }^{96,97}$

In the septin literature, this was first reported in a case of monozygotic twins with acute myeloid leukemia (AML) and a chromosomal translocation where the human celldivision cycle-related gene ( $h C D C r e l / S E P T 5)$ was found to be the fusion/partner gene to MLL. ${ }^{94}$ An additional MLL septin-like fusion gene (MSF/SEPT9) was also identified as a fusion partner to $M L L$ in a case of a therapy-related AML. ${ }^{95}$ Further research has discovered several members of the septin family that fuse to $M L L$, including SEPT2, SEPT5, SEPT6, SEPT9, and SEPT11, leading to the development of acute lymphoblastic leukemia, myelodysplastic syndromes, and AML. ${ }^{98-102}$ Quantification studies looking at fusion partners (SEPT2 and SEPT6)/MLL of gene expression demonstrated a downregulation of both MLL and its septin partner in patients with AML. ${ }^{103}$ This finding may suggest important clues in the biology of septins in relation to tumorigenesis. Indeed, the discovery that septins are fusion partners to MLL does not seem to be a casual finding, given that five different members of the gene family have been identified as fusion partners to such an extent septins have been proposed as a unique group of MLL fusion partners. ${ }^{104}$ Patients with MLL-septin fusions show a clear bias toward AML cases, and breakpoints in MLL can occur in its $5^{\prime}$ or $3^{\prime}$ region, which is in contrast with septin genes where the breaks are always found at the very $5^{\prime}$ end of known septin open reading frames. ${ }^{105}$ With technological advances in next-generation sequencing tools and with more patients being analyzed, it will be extremely interesting to observe how findings in hematological malignancies will help to elucidate mechanisms of the basic biology of septins.

Given the pivotal role that septins play in cytoskeleton dynamics and the broad range of other cellular functions, we could predict that the deregulation of septin genes has the potential to result in aberrant tissue formation, as well as affect the growth of solid tumors. The behavior of the septin genes varies based on the cancer type, acting like a tumor suppressor in some and oncogene in others. This could be explained by the fact that although septins are expressed in all tissues, the level of expression of each family member differs between cell subtypes and tissues. ${ }^{104}$

In the US from 2007 to 2011, the incidence rate of primary brain and central nervous system cancers was estimated to be 27.9 per 100,000 individuals, accounting for approximately $2 \%$ of cancers. ${ }^{106}$ Overall, they are associated with a poor prognosis and 5-year survival rates vary with differing histologies. While a large number of biomarkers are now available for the subclassification and treatment of these malignancies, the need for more precise diagnostic tools and for more effective therapies is necessary.

As mentioned earlier, several members of the septin gene family have been implicated in neurodegenerative diseases. Based on this observation and the knowledge of oncogenic functions, a potential link between septins and brain tumors 
was investigated. In particular, SEPT2 (NEDD5) has been analyzed in astrocytomas. SEPT2 was found to be expressed in a variety of brain cancer-cell lines and surgical tumors, low-grade astrocytoma, anaplastic astrocytoma, medulloblastoma, and meningioma as detected by Northern and Western analyses. When attempts were made to interfere with NEDD5/SEPT2 and decrease it in cells in culture, multinucleated cells were generated, highlighting its role in cytokinesis. ${ }^{107}$ The expression of SEPT2 has also been identified in gliomas using mass spectrometry. ${ }^{108}$ Additional studies have shown that septin genes have variable expression levels in astrocytomas and medulloblastomas. The expression of a dominant-negative mutant form of SEPT2 lead to failure of cytokinesis, creating multinucleated cells. ${ }^{109}$

An investigation of the role of SEPT7 in gliomas found that its overexpression led to inhibition of cell proliferation, while knockdown of SEPT7 caused increased cell proliferation and gliomagenesis. ${ }^{110}$ SEPT2 is mainly expressed in the brain, thus providing a direct link for alteration of function of this specific septin-family member in brain-tumor cells. Data collected on brain tumors thus far support the hypothesis that septins in this tumor type interfere with the regulation of the cell cycle. SEPT2 levels of expression were found to fluctuate within different phases of the cell cycle, suggesting that alteration of its expression level may directly impact cell-cycle progression.

Breast cancer is the most common cancer diagnosed in women. It is responsible for an estimated $29 \%$ of cancers cases each year, and it is the second-leading cause of cancer death in women. ${ }^{111}$ With respect to the septin gene family, breast cancer research has focused mainly on SEPT9 and its amplification in both mouse and human breast cancers. ${ }^{104,112}$

SEPT9 was originally identified as mapping to a region of loss of heterozygosity in breast and ovarian cancer. ${ }^{113}$ However, several lines of evidence now strongly support its putative oncogenic function. SEPT9 is a fusion partner of $M L L$ in hematological malignancies, it was identified as a hot spot of viral integration in retroviral insertion mutagenesis experiments, ${ }^{114}$ and it is amplified in the form of double-minute chromosomes. ${ }^{12}$ These are all features shared by strong oncogenes. Genomic amplification of SEPT9 has been shown to increase SEPT9 levels of expression in breast carcinomas and adenocarcinomas in human cell lines and several mouse models for human breast cancer. ${ }^{112}$ Increased levels of the transcript variant SEPT9_v1 have been found in both human cell lines and matched tumor- and peritumoral breast cancer-tissue specimens. ${ }^{115,116}$ SEPT9_v1 promotes tumor growth via an angiogenic mechanism by stabilizing HIF-1 $\alpha,{ }^{117}$ while SEPT9_v4 overexpression has been suggested as a mechanism driving resistance to microtubulesinteracting drugs. ${ }^{118}$

While the exact function that SEPT9 isoforms play in breast tumorigenesis remains unclear, several lines of evidence are now emerging suggesting that they may play important roles in breast carcinogenesis. SEPT9_v3 has been shown to be silenced by deoxyribonucleic acid (DNA) methylation upstream of the SEPT9_v3 transcription start site, and correlates with silencing in cancer cell lines. ${ }^{104}$ Overexpression of SEPT9 is seen more commonly in high-grade carcinomas, which are also associated with a worse clinical prognosis. ${ }^{116}$ SEPT9_v1 has been reported as upregulated in breast cancer and associated with oncogenic potential, possibly via its interaction with c-Jun. ${ }^{15,119}$ The promigratory phenotype of SEPT9 and its isoforms is thought to contribute to tumor metastasis and invasion in cancer subtypes where septins are overexpressed. ${ }^{120}$ Migration assays were performed on GFP-tagged SEPT9 isoforms in stable MCF7 clones, and SEPT9_v1, SEPT9_v3, SEPT9_v4, and SEPT9_v5 showed increased numbers of migratory cells, suggesting that several of the SEPT9 isoforms contribute to the migratory phenotype. ${ }^{104}$ In another cellular model, the overexpression of SEPT9 and cell motility was investigated using MDCK cells in a 3-D extracellular matrix, which aids in the morphogenesis of renal cysts. Cells with overexpression of SEPT9 doubled in cellular extensions (both in number and in length). ${ }^{20}$

Ovarian cancer is the second-most common gynecologic malignancy, and is also the most lethal. ${ }^{111}$ It can be classified into epithelial, stromal, and germ-cell subtypes, and characterized further by histology. Research conducted on the septin gene family in this malignancy has primarily focused on SEPT9 and its putative role as a tumor suppressor in this cancer type. In an analysis of 70 ovarian tumors of varying histologies (serous, mucinous, endometrioid) and of varying malignant potential (benign, borderline, and malignant), loss of heterozygosity was seen in all tumors, but greatest in those with malignant disease and $65 \%$ displaying a loss of one copy of chromosome $17 .{ }^{113}$ Alternative splice transcripts were also investigated in ovarian tumors and ovarian cancer-cell lines. They demonstrated a loss of the $\beta$-transcript (SEPT9_v4) (typically associated with normal tissue) and expression of the $\zeta$-transcript (SEPT9_v4*) appeared confined to tumor tissue $(76 \%)$, in addition to benign and borderline tumors $(60 \%-62 \%) .{ }^{121}$ Increased expression of SEPT9 was detected in serous ovarian carcinomas, but appeared most marked in 
borderline tumors, and it was not increased in any of the benign or mucinous carcinomas. SEPT9_v1 and SEPT9_v4* transcript variants were overexpressed in borderline tumors as well. ${ }^{122}$

\section{Septins as biomarkers for cancer prognosis}

The aforementioned studies implicate SEPT9 as an oncogene in human cancers, and provide evidence of its potential use as a biomarker for prognosis and clinical outcomes. The National Institutes of Health defines a biomarker as a characteristic that is objectively measured and evaluated as a marker for normal biological processes, pathological processes, or pharmacological processes to a therapeutic intervention. ${ }^{123}$ The impact of a biomarker has the potential to assist in early diagnosis of cancer or follow the treatment pattern to diagnose relapse or remission. If relapse is diagnosed, the potential for earlier initiation of treatment is made possible, although change in clinical outcomes remains questionable.

Colorectal cancer is a relatively common cancer, with both genetic and environmental predisposition. Among women and men, there is an estimated $9 \%$ incidence of new cancer cases yearly, and it is the third-leading cause of all cancer deaths. ${ }^{111}$ The most successful work in biomarker development relative to septins has been conducted in this cancer type, which will be discussed here. Current US Preventive Services Task Force recommendations for the screening of colorectal cancer include using fecal occult blood testing, colonoscopy, or sigmoidoscopy from the ages of 50 to 75 years. ${ }^{124}$ While serum markers exist for the monitoring and surveillance of colorectal cancer, they have shown limited sensitivity and specificity as screening tests, and tend to perform better when in combination. ${ }^{125}$ In other cancer subtypes, such as ovarian cancer, there are no available screening modalities. Original studies aimed to identify candidate

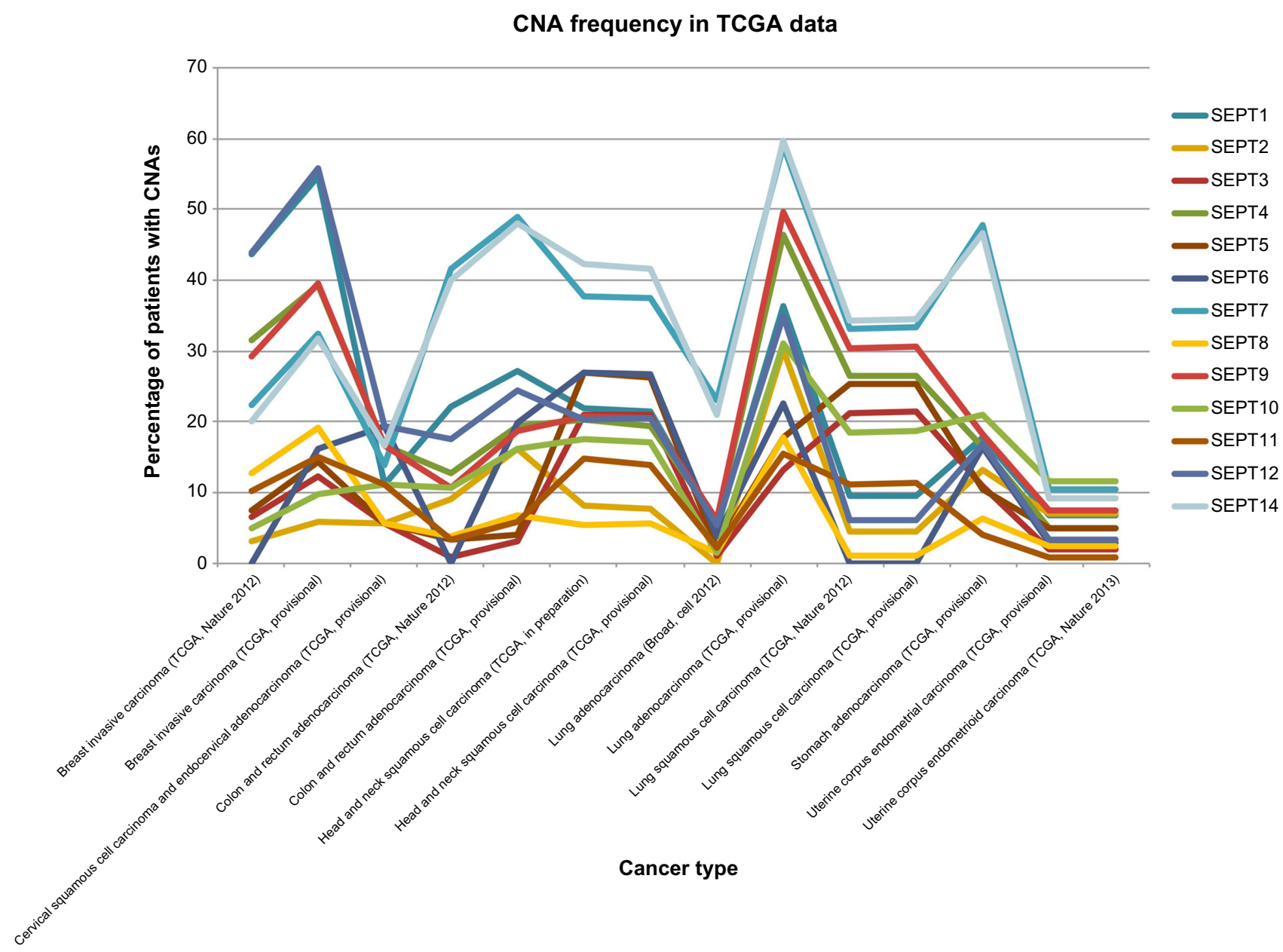

Figure 3 Plotting of frequency (y-axis) of copy-number alterations (CNAs) observed in cancer patients analyzed as part of the Cancer Genome Atlas (TCGA). Notes: Members of the septin family of genes are color-coded as indicated on the right. Tumor histologies are indicated on the $x$-axis. Breast dataset; ${ }^{45}$ colorectal dataset; ${ }^{46}$ lung carcinoma; ${ }^{47,48}$ uterine carcinoma. ${ }^{134}$ Provisional data have been plotted by searching the CBioPortal for Cancer Genomics. ${ }^{128,135}$ 
biomarkers in peripheral blood based on the methylation status of cell-free DNA in cancer patients identified septins as potential biomarkers based on the finding that elevated concentrations of methylated SEPT9 were present in their plasma. ${ }^{126}$ Validation studies were performed to identify hypermethylated SEPT9 DNA in colon cancer patients of all stages, and reported $72 \%$ sensitivity and $90 \%$ specificity by adding a technical replicate to the measure of methyl SEPT9. ${ }^{127}$ As results of the studies on SEPT9 in colorectal cancer, a commercial test (ColoVantage; methylated septin 9) is now available trough Quest Diagnostics.

This technique has also been explored in other cancers where sensitive biomarkers for early detection are lacking, such as lung cancer. A study detected hypermethylation of the SEPT9 promoter in $44.3 \%$ of lung cancer cases of all stages and histologic subtypes. ${ }^{128}$ This work is however preliminary, and further studies are required to determine if noninvasive DNA methylation assays of septin genes are suitable as biomarkers in other cancer types.
In an attempt to explore a possible role of septins as biomarkers in hematological malignancies and solid tumors, our group performed an analysis of the copy number and mutational status of all septins in several tumors of different histological subtypes for a total of over 11,000 samples covering more than 30 anatomical sites. ${ }^{104}$ The samples have been sequenced using whole-genome and whole-exome analysis as part of the Cancer Genome Atlas (TCGA) initiative. ${ }^{129,130}$ Globally speaking, the majority of solid tumors appear to have an alteration in copy-number variation when compared to mutational status within the same grouping of tumors (by querying both published and provisional data provided as of October 2013). This result is consistent with previous observations. ${ }^{131,132}$ There is a range of gain seen in epithelial tumors, with the largest alterations in breast and lung cancers. In both provisional and published breast cancer data sets, the greatest gain is seen in SEPT1 (43.6\% reported in the published data set, $54.6 \%$ reported in the provisional dataset), SEPT9 (29.3\%, 39.6\%), and SEPT12 (44\%, 55.7\%)

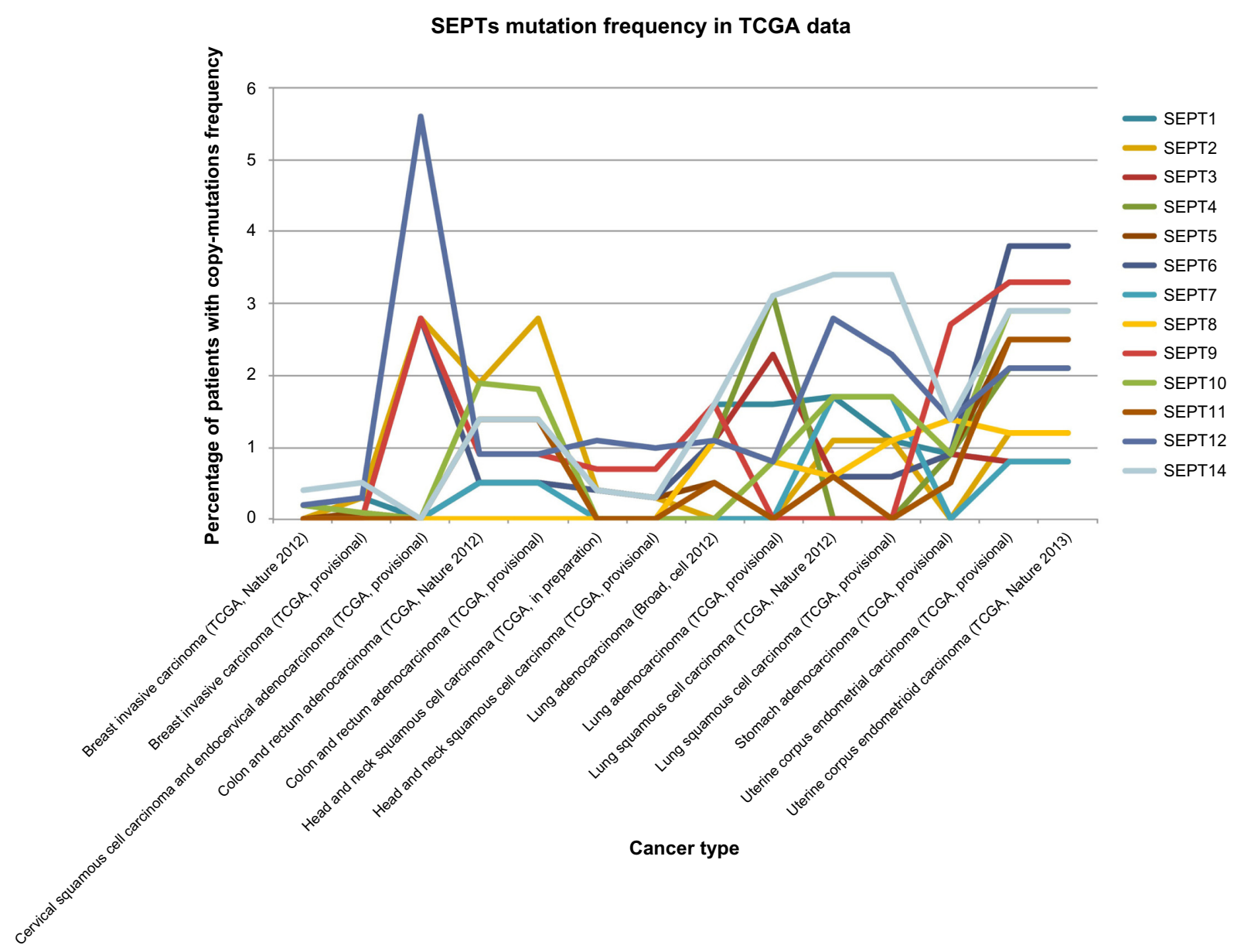

Figure 4 Plotting of mutation frequency (y-axis) observed in cancer patients analyzed as part of the Cancer Genome Atlas (TCGA).

Notes: Members of the septin family of genes are color-coded as indicated on the right. Tumor histologies are indicated on the $x$-axis. Breast dataset; ${ }^{45}$ colorectal dataset; ${ }^{46}$ lung carcinoma; ${ }^{47,48}$ uterine carcinoma. ${ }^{134}$ Provisional data have been plotted by searching the CBioPortal for Cancer Genomics. ${ }^{128,135}$ 
(Figure 3). Similarly, in lung cancer, the greatest gain is observed in SEPT1 (4.9\%, 36.4\%), SEPT4 (6\%, 46.5\%), SEPT7 (23.1\%, 58.9\%), SEPT9 (6\%, 49.6\%), SEPT12 (5.5\%, $34.9 \%$ ), and SEPT14 (20.9\%, 59.7\%). However, this degree of genetic alteration is not observed when mutational status is interrogated. The percentage of cases with mutations in SEPT6 is greatest in the cervical cancer group, with $5.6 \%$ of patients found to have a mutation. The remaining cancer types have less than $5 \%$ of cases with a mutation in septin (Figure 4). Interestingly, when all septins were analyzed as a group (13 members) the most frequently altered tumor subtype was bladder urothelial carcinoma, with a total of $37.8 \%(n=127)$ cases harboring a genomic alteration in one or more septins. The tumor type with the lowest frequency of alterations was thyroid carcinoma ( $1 \%$ of cases, $n=399)$. Of interest, a previous report indicated that SEPT9 was not found to be mutated in breast cancer. ${ }^{131}$ The TCGA data support this observation; however, the sequencing results uncover several mutations present in tumors of other histological subtypes, with skin cutaneous melanoma presenting SEPT9 mutations in $1.9 \%$ of the cases $(n=262)$. Interestingly, these mutations, even though relatively rare, cluster within the septin canonical domains: polybasic region, GTPase domain, and the septin-unique domain (Montagna and Zechmeister, unpublished observations).

\section{Conclusion and perspectives}

The septin genes were discovered in budding yeast four decades ago, ${ }^{1-3}$ and their expression in mammalian cells has been known for about 20 years. ${ }^{133}$ While our knowledge of the structure and mechanisms of filament assembly in yeast has been expanding, the functions that septins play in mammalian cells are just emerging. It is quite intriguing that the majority of functions that have been characterized by studying eukaryotic microorganisms seem to be maintained in mammalian cells, a parallel strongly supporting the unambiguous essential role that septins play in cytokinesis, cell polarity, and establishment of diffusion barriers. ${ }^{134}$ Despite the large body of work, many questions remain unanswered. For instance the mechanism of function of the most conserved domain, the GTP-binding domain, still awaits further resolution: what is the role of GTP binding and hydrolysis, and how do the dynamics of hydrolysis affect the 3-D structure of the septin complexes? Likewise, the mechanisms of assembly of septin filaments, the number, the structure, and the composition of septin hexamers and octamers remain poorly understood.

With the discovery of septins as being altered in a large number of human diseases, novel functions may emerge.
Likewise, the mapping of rare variants by the increasing number of next-generation whole-exome and whole-genome sequencing may help pinpoint important nucleotides or regions of interest. For example, the function of the N-terminal domain of SEPT9 has been brought to center stage because of the identification of mutations in HNA patients. ${ }^{88}$ Following this discovery, functional studies aimed at better understanding of the function of this specific region have been carried out, such that it was revealed that the $\mathrm{N}$-terminal domain of SEPT9 is required for unique interactions with SEPT4 and SEPT $11,{ }^{92}$ that is necessary for binding to microtubule bundles, ${ }^{42}$ and that is essential to rescue cytokinesis defects in septin-depletion experiments. ${ }^{39}$

As more associations of septins with dysfunction in human diseases are uncovered, more data for targeted analysis of regions of particular interest will become available, aiding in new discoveries and better characterization of septin functions.

\section{Disclosure}

The authors report no conflicts of interest in this work.

\section{References}

1. Byers B, Goetsch L. A highly ordered ring of membrane-associated filaments in budding yeast. $J$ Cell Biol. 1976;69:717-721.

2. Hartwell LH. Genetic control of the cell division cycle in yeast. IV. Genes controlling bud emergence and cytokinesis. Exp Cell Res. 1971;69:265-276.

3. Longtine MS, DeMarini DJ, Valencik ML, et al. The septins: roles in cytokinesis and other processes. Curr Opin Cell Biol. 1996;8: 106-119.

4. Nishihama R, Onishi M, Pringle JR. New insights into the phylogenetic distribution and evolutionary origins of the septins. Biol Chem. 2011;392:681-687.

5. McMurray MA, Bertin A, Garcia G 3rd, Lam L, Nogales E, Thorner J. Septin filament formation is essential in budding yeast. Dev Cell 20. 2011;20:540-549.

6. Cooper JA, Kiehart DP. Septins may form a ubiquitous family of cytoskeletal filaments. J Cell Biol. 1996;134:1345-1348.

7. Mostowy S, Bonazzi M, Hamon MA, et al. Entrapment of intracytosolic bacteria by septin cage-like structures. Cell Host Microbe. 2010;8:433-444

8. Kinoshita M, Field CM, Coughlin ML, Straight AF, Mitchison TJ. Self- and actin-templated assembly of mammalian septins. Dev Cell. 2002;3:791-802.

9. Vrabioiu AM, Mitchison TJ. Structural insights into yeast septin organization from polarized fluorescence microscopy. Nature. 2006;443 466-469.

10. Rodal AA, Kozubowski L, Goode BL, Drubin DG, Hartwig JH. Actin and septin ultrastructures at the budding yeast cell cortex. Mol Biol Cell. 2005;16:372-384.

11. Versele M, Gullbrand B, Shulewitz MJ, et al. Protein-protein interactions governing septin heteropentamer assembly and septin filament organization in Saccharomyces cerevisiae. Mol Biol Cell. 2004;15:4568-4583.

12. Cao L, Ding X, Yu W, Yang X, Shen S, Yu L. Phylogenetic and evolutionary analysis of the septin protein family in metazoan. FEBS Lett. 2007;581:5526-5532. 
13. Kinoshita M. Assembly of mammalian septins. J Biochem. 2003;134: 491-496.

14. Weirich CS, Erzberger JP, Barral Y. The septin family of GTPases: architecture and dynamics. Nat Rev Mol Cell Biol. 2008;9:478-489.

15. Pan F, Malmberg RL, Momany M. Analysis of septins across kingdoms reveals orthology and new motifs. BMC Evol Biol. 2007;7:103.

16. Casamayor A, Snyder M. Molecular dissection of a yeast septin: distinct domains are required for septin interaction, localization, and function. Mol Cell Biol. 2003;23;2762-2777.

17. Meseroll RA, Howard L, Gladfelter AS. Septin ring size scaling and dynamics require the coiled-coil region of Shs1p. Mol Biol Cell. 2012;23:3391-3406.

18. Bertin A, McMurray MA, Grob P, et al. Saccharomyces cerevisiae septins: supramolecular organization of heterooligomers and the mechanism of filament assembly. Proc Natl Acad Sci U SA. 2008;105; 8274-8279.

19. Low C, Macara IG. Structural analysis of septin 2, 6, and 7 complexes. J Biol Chem. 2006;281:30697-30706.

20. Dolat L, Hu Q, Spiliotis ET. Septin functions in organ system physiology and pathology. Biol Chem. 2014;395:123-141.

21. Huang YW, Surka MC, Reynaud D, Pace-Asciak C, Trimble WS. GTP binding and hydrolysis kinetics of human septin 2. FEBS J. 2006;273: $3248-3260$

22. Farkasovsky M, Herter P, Voss B, Wittinghofer A. Nucleotide binding and filament assembly of recombinant yeast septin complexes. Biol Chem. 2005;386:643-656.

23. Zent E, Wittinghofer A. Human septin isoforms and the GDP-GTP cycle. Biol Chem. 2014;395:169-180.

24. Sirajuddin M, Farkasovsky M, Zent E, Wittinghofer A. GTP-induced conformational changes in septins and implications for function. Proc Natl Acad Sci U S A. 2009;106:16592-16597.

25. Vetter IR, Wittinghofer A. The guanine nucleotide-binding switch in three dimensions. Science. 2001;294:1299-1304.

26. Zhang J, Kong C, Xie H, McPherson PS, Grinstein S, Trimble WS. Phosphatidylinositol polyphosphate binding to the mammalian septin H5 is modulated by GTP. Curr Biol. 1999;9:1458-1467.

27. Kremer BE, Haystead T, Macara IG. Mammalian septins regulate microtubule stability through interaction with the microtubule-binding protein MAP4. Mol Biol Cell. 2005;16:4648-4659.

28. Kay BK, Williamson MP, Sudol M. The importance of being proline: the interaction of proline-rich motifs in signaling proteins with their cognate domains. FASEB J. 2000;14:231-241.

29. Pham T, DiCiccio JE, Trimble WS. Cytoskeleton: septins do the horizontal tango. Curr Biol. 2014;24:R324-R327.

30. John CM, Hite RK, Weirich CS, et al. The Caenorhabditis elegans septin complex is nonpolar. EMBO J. 2007;26:3296-3307.

31. Sirajuddin M, Farkasovsky M, Hauer F, et al. Structural insight into filament formation by mammalian septins. Nature. 2007;449:311-315.

32. de Almeida Marques I, Valadares NF, Garcia W, et al. Septin C-terminal domain interactions: implications for filament stability and assembly. Cell Biochem Biophys. 2012;62:317-328.

33. Joberty G, Perlungher RR, Sheffield PJ, et al. Borg proteins control septin organization and are negatively regulated by $\mathrm{Cdc} 42$. Nat Cell Biol. 2001;3:861-866.

34. Fujishima K, Kiyonari H, Kurisu J, Hirano T, Kengaku M. Targeted disruption of Sept3, a heteromeric assembly partner of Sept5 and Sept7 in axons, has no effect on developing CNS neurons. $J$ Neurochem. 2007;102:77-92.

35. Xie Y, Vessey JP, Konecna A, Dahm R, Macchi P, Kiebler MA. The GTP-binding protein Septin 7 is critical for dendrite branching and dendritic-spine morphology. Curr Biol. 2007;17:1746-1751.

36. Nagata $\mathrm{K}$, Asano T, Nozawa $Y$, Inagaki M. Biochemical and cell biological analyses of a mammalian septin complex, Sept7/9b/11. J Biol Chem. 2004;279:55895-55904.

37. Sellin ME, Sandblad L, Stenmark S, Gullberg M. Deciphering the rules governing assembly order of mammalian septin complexes. Mol Biol Cell. 2011;22:3152-3164.
38. Surka MC, Tsang CW, Trimble WS. The mammalian septin MSF localizes with microtubules and is required for completion of cytokinesis. Mol Biol Cell. 2002;13:3532-3545.

39. Estey MP, Di Ciano-Oliveira C, Froese CD, Bejide MT, Trimble WS. Distinct roles of septins in cytokinesis: SEPT9 mediates midbody abscission. J Cell Biol. 2010;191:741-749.

40. Kim MS, Froese CD, Estey MP, Trimble WS. SEPT9 occupies the terminal positions in septin octamers and mediates polymerizationdependent functions in abscission. J Cell Biol. 2011;195:815-826.

41. Mostowy S, Cossart P. Septins: the fourth component of the cytoskeleton. Nat Rev Mol Cell Biol. 2012;13:183-194.

42. Bai X, Bowen JR, Knox TK, et al. Novel septin 9 repeat motifs altered in neuralgic amyotrophy bind and bundle microtubules. $J$ Cell Biol. 2013;203:895-905.

43. Cooper TG. Cytoplasmic droplets: the good, the bad or just confusing? Hum Reprod. 2005;20:9-11.

44. Mavrakis M, Azou-Gros Y, Tsai FC, et al. Septins promote F-actin ring formation by crosslinking actin filaments into curved bundles. Nat Cell Biol. 2014;16:322-334.

45. Johnson ES, Gupta AA. An E3-like factor that promotes SUMO conjugation to the yeast septins. Cell. 2001;106:735-744.

46. Joo E, Surka MC, Trimble WS. Mammalian SEPT2 is required for scaffolding nonmuscle myosin II and its kinases. Dev Cell. 2007;13: 677-690.

47. Spiliotis ET, Hunt SJ, Hu Q, Kinoshita M, Nelson WJ. Epithelial polarity requires septin coupling of vesicle transport to polyglutamylated microtubules. J Cell Biol. 2008;180:295-303.

48. Beites CL, Xie H, Bowser R, Trimble WS. The septin CDCrel-1 binds syntaxin and inhibits exocytosis. Nat Neurosci. 1999;2:434-439.

49. Barral Y, Parra M, Bidlingmaier S, Snyder M. Nim1-related kinases coordinate cell cycle progression with the organization of the peripheral cytoskeleton in yeast. Genes Dev. 1999;13:176-187.

50. Hanrahan J, Snyder M. Cytoskeletal activation of a checkpoint kinase. Mol Cell. 2003;12:663-673.

51. Longtine MS, Theesfeld CL, McMillan JN, Weaver E, Pringle JR, Lew DJ. Septin-dependent assembly of a cell cycle-regulatory module in Saccharomyces cerevisiae. Mol Cell Biol. 2000;20:4049-4061.

52. Vrabioiu AM, Gerber SA, Gygi SP, Field CM, Mitchison TJ. The majority of the Saccharomyces cerevisiae septin complexes do not exchange guanine nucleotides. J Biol Chem. 2004;279:3111-3118.

53. Kinoshita M. Diversity of septin scaffolds. Curr Opin Cell Biol. 2006;18:54-60.

54. Kusch J, Meyer A, Snyder MP, Barral Y. Microtubule capture by the cleavage apparatus is required for proper spindle positioning in yeast. Genes Dev. 2002;16:1627-1639.

55. Barral Y, Mermall V, Mooseker MS, Snyder M. Compartmentalization of the cell cortex by septins is required for maintenance of cell polarity in yeast. Mol Cell. 2000;5:841-851.

56. Takizawa PA, DeRisi JL, Wilhelm JE, Vale RD. Plasma membrane compartmentalization in yeast by messenger RNA transport and a septin diffusion barrier. Science. 2000;290:341-344.

57. Dobbelaere J, Barral Y. Spatial coordination of cytokinetic events by compartmentalization of the cell cortex. Science. 2004;305: 393-396.

58. Saarikangas J, Barral Y. The emerging functions of septins in metazoans. EMBO Rep. 2011;12:1118-1126.

59. Schmidt K, Nichols BJ. A barrier to lateral diffusion in the cleavage furrow of dividing mammalian cells. Curr Biol. 2004;14: 1002-1006.

60. Satir P, Pedersen LB, Christensen ST. The primary cilium at a glance. J Cell Sci. 2010;123:499-503.

61. Hu Q, Milenkovic L, Jin H, et al. A septin diffusion barrier at the base of the primary cilium maintains ciliary membrane protein distribution. Science. 2010;329:436-439.

62. Ihara M, Kinoshita A, Yamada S, et al. Cortical organization by the septin cytoskeleton is essential for structural and mechanical integrity of mammalian spermatozoa. Dev Cell. 2005;8:343-352. 
63. Kissel H, Georgescu MM, Larisch S, Manova K, Hunnicutt GR, Steller H. The Sept4 septin locus is required for sperm terminal differentiation in mice. Dev Cell. 2005;8:353-364.

64. Steels JD, Estey MP, Froese CD, Reynaud D, Pace-Asciak C, Trimble WS. Sept12 is a component of the mammalian sperm tail annulus. Cell Motil Cytoskeleton. 2007;64:794-807.

65. Tada T, Simonetta A, Batterton M, Kinoshita M, Edbauer D, Sheng M. Role of septin cytoskeleton in spine morphogenesis and dendrite development in neurons. Curr Biol. 2007;17:1752-1758.

66. Buser AM, Erne B, Werner HB, Nave KA, Schaeren-Wiemers N. The septin cytoskeleton in myelinating glia. Mol Cell Neurosci. 2009;40: 156-166.

67. Patzig J, Jahn O, Tenzer S, et al. Quantitative and integrative proteome analysis of peripheral nerve myelin identifies novel myelin proteins and candidate neuropathy loci. J Neurosci. 2011;31:16369-16386.

68. Kim SK, Shindo A, Park TJ, et al. Planar cell polarity acts through septins to control collective cell movement and ciliogenesis. Science. 2010;329:1337-1340.

69. McCaffrey LM, Macara IG. Widely conserved signaling pathways in the establishment of cell polarity. Cold Spring Harb Perspect Biol. 2009; 1:a001370.

70. Pringle JR, Bi E, Harkins HA, et al. Establishment of cell polarity in yeast. Cold Spring Harb Symp Quant Biol. 1995;60:729-744.

71. Drubin DG, Nelson WJ. Origins of cell polarity. Cell. 1996;84: 335-344.

72. Bowen JR, Hwang D, Bai X, Roy D, Spiliotis ET. Septin GTPases spatially guide microtubule organization and plus end dynamics in polarizing epithelia. J Cell Biol. 2011;194:187-197.

73. Spiliotis ET, Kinoshita M, Nelson WJ. A mitotic septin scaffold required for mammalian chromosome congression and segregation. Science. 2005;307:1781-1785.

74. Nagata K, Kawajiri A, Matsui S, et al. Filament formation of MSF-A, a mammalian septin, in human mammary epithelial cells depends on interactions with microtubules. J Biol Chem. 2003;278:18538-18543.

75. Spiliotis ET. Regulation of microtubule organization and functions by septin GTPases. Cytoskeleton. 2010;67:339-345.

76. Huang YW, Yan M, Collins RF, Diciccio JE, Grinstein S, Trimble WS. Mammalian septins are required for phagosome formation. Mol Biol Cell. 2008;19:1717-1726.

77. Mostowy S, Nam Tham T, Danckaert A, et al. Septins regulate bacterial entry into host cells. PloS One. 2009;4:e4196.

78. Tooley AJ, Gilden J, Jacobelli J, et al. Amoeboid T lymphocytes require the septin cytoskeleton for cortical integrity and persistent motility. Nat Cell Biol. 2009;11:17-26.

79. Lassen LB, Füchtbauer A, Schmitz A, Sørensen AB, Pedersen FS, Füchtbauer EM. Septin9 is involved in T-cell development and CD8+ T-cell homeostasis. Cell Tissue Res. 2013;352:695-705.

80. Kinoshita A, Kinoshita M, Akiyama H, et al. Identification of septins in neurofibrillary tangles in Alzheimer's disease. Am J Pathol. 1998;153: 1551-1560.

81. Ihara M, Tomimoto H, Kitayama H, et al. Association of the cytoskeletal GTP-binding protein Sept4/H5 with cytoplasmic inclusions found in Parkinson's disease and other synucleinopathies. J Biol Chem. 2003;278:24095-24102.

82. Shehadeh L, Mitsi G, Adi N, Bishopric N, Papapetropoulos S. Expression of Lewy body protein septin 4 in postmortem brain of Parkinson's disease and control subjects. Mov Disord. 2009;24:204-210.

83. Pennington K, Beasley CL, Dicker P, et al. Prominent synaptic and metabolic abnormalities revealed by proteomic analysis of the dorsolateral prefrontal cortex in schizophrenia and bipolar disorder. Mol Psychiatry. 2008;13:1102-1117.

84. Engidawork E, Gulesserian T, Fountoulakis M, Lubec G. Aberrant protein expression in cerebral cortex of fetus with Down syndrome. Neuroscience. 2003;122:145-154.

85. Walikonis RS, Jensen ON, Mann M, Provance DW Jr, Mercer JA, Kennedy MB. Identification of proteins in the postsynaptic density fraction by mass spectrometry. J Neurosci. 2000;20:4069-4080.
86. Kalikin LM, Sims HL, Petty EM. Genomic and expression analyses of alternatively spliced transcripts of the MLL septin-like fusion gene (MSF) that map to a $17 \mathrm{q} 25$ region of loss in breast and ovarian tumors. Genomics. 2000;63:165-172.

87. McIlhatton MA, Burrows JF, Donaghy PG, Chanduloy S, Johnston PG, Russell SE. Genomic organization, complex splicing pattern and expression of a human septin gene on chromosome 17q25.3. Oncogene. 2001;20:5930-5939.

88. Kuhlenbäumer G, Hannibal MC, Nelis E, et al. Mutations in SEPT9 cause hereditary neuralgic amyotrophy. Nat Genet. 2005;37: 1044-1046.

89. Hannibal MC, Ruzzo EK, Miller LR, et al. SEPT9 gene sequencing analysis reveals recurrent mutations in hereditary neuralgic amyotrophy. Neurology. 2009;72:1755-1759.

90. Collie AM, Landsverk ML, Ruzzo E, et al. Non-recurrent SEPT9 duplications cause hereditary neuralgic amyotrophy. J Med Genet. 2010;47:601-607.

91. Landsverk ML, Ruzzo EK, Mefford HC, et al. Duplication within the SEPT9 gene associated with a founder effect in North American families with hereditary neuralgic amyotrophy. Hum Mol Genet. 2009; 18:1200-1208.

92. Sudo K, Ito H, Iwamoto I, Morishita R, Asano T, Nagata K. SEPT9 sequence alternations causing hereditary neuralgic amyotrophy are associated with altered interactions with SEPT4/SEPT11 and resistance to Rho/Rhotekin-signaling. Hum Mutat. 2007;28:1005-1013.

93. Kuo YC, Lin YH, Chen HI, et al. SEPT12 mutations cause male infertility with defective sperm annulus. Hum Mutat. 2012;33:710-719.

94. Megonigal MD, Rappaport EF, Jones DH, et al. t(11;22)(q23;q11.2) In acute myeloid leukemia of infant twins fuses MLL with hCD$\mathrm{Crel}$, a cell division cycle gene in the genomic region of deletion in DiGeorge and velocardiofacial syndromes. Proc Natl Acad Sci USA. 1998;95:6413-6418.

95. Osaka M, Rowley JD, Zeleznik-Le NJ. MSF (MLL septin-like fusion), a fusion partner gene of MLL, in a therapy-related acute myeloid leukemia with a t(11;17)(q23;q25). Proc Natl Acad Sci USA. 1999;96:6428-6433.

96. Rabbitts TH. Chromosomal translocations in human cancer. Nature. 1994;372:143-149.

97. Thirman MJ, Gill HJ, Burnett RC, et al. Rearrangement of the MLL gene in acute lymphoblastic and acute myeloid leukemias with 11q23 chromosomal translocations. N Engl J Med. 1993;329:909-914.

98. Borkhardt A, Teigler-Schlegel A, Fuchs U, et al. An ins(X;11) (q24;q23) fuses the MLL and the Septin 6/KIAA0128 gene in an infant with AML-M2. Genes Chromosomes Cancer. 2001;32:82-88.

99. Yamamoto K, Shibata F, Yamaguchi M, Miura O. Fusion of MLL and MSF in adult de novo acute myelomonocytic leukemia (M4) with $\mathrm{t}(11 ; 17)(\mathrm{q} 23 ; \mathrm{q} 25)$. Int $J$ Hematol. 2002;75:503-507.

100. Kreuziger LM, Porcher JC, Ketterling RP, Steensma DP. An MLL-SEPT9 fusion and $\mathrm{t}(11 ; 17)(\mathrm{q} 23 ; \mathrm{q} 25)$ associated with de novo myelodysplastic syndrome. Leuk Res. 2007;31:1145-1148.

101. Kurosu T, Tsuji K, Ohki M, et al. A variant-type MLL/SEPT9 fusion transcript in adult de novo acute monocytic leukemia (M5b) with $\mathrm{t}(11 ; 17)(\mathrm{q} 23 ; \mathrm{q} 25)$. Int J Hematol. 2008;88:192-196.

102. Stevens SJ, Meers LE, Albrechts JC, et al. A translocation in acute lymphoblastic leukemia that cytogenetically mimics the recurrent MLL-AFF1 translocation and fuses SEPT11 to MLL. Cancer Genet Cytogenet. 2010;201:48-51.

103. Cerveira N, Santos J, Teixeira MR. Structural and expression changes of septins in myeloid neoplasia. Crit Rev Oncog. 2009;15:91-115.

104. Connolly D, Yang Z, Castaldi M, et al. Septin 9 isoform expression, localization and epigenetic changes during human and mouse breast cancer progression. Breast Cancer Res. 2011;13:R76.

105. Cerveira N, Bizarro S, Teixeira MR. MLL-SEPTIN gene fusions in hematological malignancies. Biol Chem. 2011;392:713-724.

106. Ostrom QT, Bauchet L, Davis FG, et al. The epidemiology of glioma in adults: a "state of the science" review. Neuro Oncol. 2014;16: 896-913. 
107. Sakai K, Kurimoto M, Tsugu A, Hubbard SL, Trimble WS, Rutka JT. Expression of Nedd5, a mammalian septin, in human brain tumors. J Neurooncol. 2002;57:169-177.

108. Khalil AA. Biomarker discovery: a proteomic approach for brain cancer profiling. Cancer Sci. 2007;98:201-213.

109. Kim DS, Hubbard SL, Peraud A, Salhia B, Sakai K, Rutka JT. Analysis of mammalian septin expression in human malignant brain tumors. Neoplasia. 2004;6:168-178.

110. Jia ZF, Huang Q, Kang CS, et al. Overexpression of septin 7 suppresses glioma cell growth. J Neurooncol. 2010;98:329-340.

111. Siegel R, Naishadham D, Jemal A. Cancer statistics, 2012. CA Cancer J Clin. 2012;62:10-29.

112. Montagna C, Lyu MS, Hunter K, et al. The septin 9 (MSF) gene is amplified and overexpressed in mouse mammary gland adenocarcinomas and human breast cancer cell lines. Cancer Res. 2003;63: 2179-2187.

113. Russell SE, McIlhatton MA, Burrows JF, et al. Isolation and mapping of a human septin gene to a region on chromosome $17 \mathrm{q}$, commonly deleted in sporadic epithelial ovarian tumors. Cancer Res. 2000;60: 4729-4734.

114. Sørensen AB, Warming S, Füchtbauer EM, Pedersen FS. Alternative splicing, expression, and gene structure of the septin-like putative proto-oncogene Sint1. Gene. 2002;285:79-89.

115. Gonzalez ME, Peterson EA, Privette LM, Loffreda-Wren J, Kalikin LM, Petty EM. High SEPT9_v1 expression in human breast cancer cells is associated with oncogenic phenotypes. Cancer Res. 2007;67: 8554-8564.

116. Connolly D, Hoang HG, Adler E, et al. Septin 9 amplification and isoform-specific expression in peritumoral and tumor breast tissue. Biol Chem. 2014;395:157-167.

117. Amir S, Golan M, Mabjeesh NJ. Targeted knockdown of SEPT9_v1 inhibits tumor growth and angiogenesis of human prostate cancer cells concomitant with disruption of hypoxia-inducible factor-1 pathway. Mol Cancer Res. 2010;8:643-652.

118. Chacko AD, McDade SS, Chanduloy S, et al. Expression of the SEPT9_i4 isoform confers resistance to microtubule-interacting drugs. Cell Oncol (Dordr). 2012;35:85-93.

119. Gonzalez ME, Makarova O, Peterson EA, Privette LM, Petty EM. Up-regulation of SEPT9_v1 stabilizes c-Jun-N-terminal kinase and contributes to its pro-proliferative activity in mammary epithelial cells. Cell Signal. 2009;21:477-487.

120. Chacko AD, Hyland PL, McDade SS, Hamilton PW, Russell SH, Hall PA. SEPT9_v4 expression induces morphological change, increased motility and disturbed polarity. J Pathol. 2005;206: $458-465$.
121. Burrows JF, Chanduloy S, McIlhatton MA, et al. Altered expression of the septin gene, SEPT9, in ovarian neoplasia. J Pathol. 2003;201: 581-588.

122. Scott M, McCluggage WG, Hillan KJ, Hall PA, Russell SE. Altered patterns of transcription of the septin gene, SEPT9, in ovarian tumorigenesis. Int J Cancer. 2006;118:1325-1329.

123. Foundation for the National Institutes of Health. Key initiatives: Biomarkers Consortium. 2014. Available from: http:/www.fnih.org/ work/key-initiatives/biomarkers-consortium. Accessed January 17, 2015.

124. Final Recommendation Statement: Colorectal Cancer: Screening. US Preventive Services Task Force. October 2014. Available from http://www.uspreventiveservicestaskforce.org/Page/Document/ RecommendationStatementFinal/colorectal-cancer-screening. Accessed January 30, 2015.

125. Wild N, Andres H, Rollinger W, et al. A combination of serum markers for the early detection of colorectal cancer. Clin Cancer Res. 2010;16: 6111-6121.

126. Lofton-Day C, Model F, Devos T, et al. DNA methylation biomarkers for blood-based colorectal cancer screening. Clin Chem. 2008;54: 414-423.

127. Grützmann R, Molnar B, Pilarsky C, et al. Sensitive detection of colorectal cancer in peripheral blood by septin 9 DNA methylation assay. PloS One. 2008;3:e3759.

128. Powrózek T, Krawczyk P, Kucharczyk T, Milanowski J. Septin 9 promoter region methylation in free circulating DNA - potential role in noninvasive diagnosis of lung cancer: preliminary report. Med Oncol. 2014;31:917.

129. Cerami E, Gao J, Dogrusoz U, et al. The cBio cancer genomics portal: an open platform for exploring multidimensional cancer genomics data. Cancer Discov. 2012;2:401-404.

130. National Cancer Institute. The Cancer Genome Atlas. Available from: http://cancergenome.nih.gov. Accessed January 17, 2015.

131. Robertson C, Church SW, Nagar HA, Price J, Hall PA, Russell SE. Properties of SEPT9 isoforms and the requirement for GTP binding. J Pathol. 2004;203:519-527.

132. Scott M, Hyland PL, McGregor G, Hillan KJ, Russell SE, Hall PA. Multimodality expression profiling shows SEPT9 to be overexpressed in a wide range of human tumours. Oncogene. 2005;24: 4688-4700.

133. Wright SD, Ramos RA, Patel M, Miller DS. Septin: a factor in plasma that opsonizes lipopolysaccharide-bearing particles for recognition by CD14 on phagocytes. J Exp Med. 1992;176:719-727.

134. Oh Y, Bi E. Septin structure and function in yeast and beyond. Trends Cell Biol. 2011;21:141-148.
Research and Reports in Biochemistry

\section{Publish your work in this journal}

Research and Reports in Biochemistry is an international, peer-reviewed, open access journal publishing original research, reports, reviews and commentaries on all areas of biochemistry. The manuscript management system is completely online and includes a very quick and fair

\section{Dovepress}

peer-review system. Visit http://www.dovepress.com/testimonials.php to read real quotes from published authors. 